\title{
THE CURRENT STATUS OF FERTILITY CONTROL
}

\section{Christopher TIETZE*}

About two-thirds of the human race inhabit those regions of the world where the practice of birth control is sufficiently limited to make it appropriate to refer to them as regions of uncontrolled fertility. In these areas, the annual birth rate ranges between about forty and fifty per $\mathrm{x}, 000$ population. The remaining one-third of the world's people inhabits areas where fertility is comparatively well-controlled-North America, Europe (including the Soviet Union), the temperate zones of South America and Oceania, and Japan. In most of the countries of these regions, the annual birth rate in recent years has ranged from about fifteen to twenty-five per r,000 population. ${ }^{1}$

This article discusses the methods employed to control fertility, and the extent and effectiveness of their use in the United States and other countries. From a biological point of view, all of these methods may be conveniently grouped into four categories: (I) abstinence, (2) contraception, (3) sterilization, and (4) abortion. From a sociological point of view, delayed marriage and permanent celibacy, as well as other customs reducing the proportion married among the population of reproductive age, must also be considered to be methods of fertility control, since in most societies, varying degrees of restraint are imposed on the sexual activities of unmarried persons.

\section{I}

\section{Abstinence}

Ireland is the classical example of a country where social institutions serve as effective restraints on population growth. According to the Irish census of 1951, about thirty-one per cent of the men and twenty-six per cent of the women at fifty years of age had never married, as compared with about eight per cent for either sex in the United States. The average age at first marriage was thirty-one years for Irish grooms and twenty-seven years for Irish brides, as compared with twenty-four years and twenty-one years for American grooms and brides, respectively. ${ }^{2}$ Since fertility within marriage in Ireland is only one-fifth below the level that might be expected if no birth control were practiced by the population, the birth rate on

* M.D. 1932, University of Vienna, Austria. Director of Research, National Committec on' Maternal Fealth, Inc. Author, The Clinicax. Effectiveness of Contraceptive Methods (i959); The Condom as a Contraceptrve (1960). Contributor to periodicals of articles in the fields of medical statistics and demography.

${ }^{1}$ U.N. Dep't of Economic and Social AfFatrs, Report on World Social Situation 6-iz (ST/SOA/ 33) (U.N. Pub. Sales No. I957.IV.3).

2 U.N. Dep't of Economic and Social AfFairs, Demographic Yearboox 396-97, 418-19 (U.N. Pub. Sales No. 1955.XIII.6). Cf. Hajnal, Age at Marriage and Proportions Marrying, 7 Pop. STUDIEs III (I953). 
the Emerald Isle would be between thirty-five and forty per I,000 population if Irish women married in the same proportions and as early in life as American women. Thus, a devout Roman Catholic population exercises a high level of fertility control primarily by marrying late in life, or not at all. In all other countries of the world, reductions in birth rates have been achieved through control of fertility within marriage.

Although abstinence from coitus, with or without recourse to forms of sexual gratification not involving genital union, is a fool-proof method of fertility control, it is not acceptable to the great majority of married men and women in all cultures. In a recent American investigation, prolonged abstinence was reported by only two per cent of the respondents as a method of family limitation they had used. ${ }^{3}$

II

\section{Contraception}

The term contraception, in the usage of most writers on the subject, encompasses all nonpermanent measures to prevent coitus from resulting in conception. It excludes sterilization as well as abstinence and abortion. Birth control is generally employed as a synonym.

\section{A. Methods}

In demographic literature, it is customary to distinguish between "appliance methods" (e.g., mechanical devices or spermicides) and "non-appliance methods" (e.g., coitus interruptus or the rhythm method). This dichotomy makes no provision for the oral contraceptives now being developed. The Roman Catholic Church distinguishes between "natural birth control" (periodic continence-i.e., the rhythm method), which it condones, and "artificial birth control" (comprising all other methods), which it condemns.

The following is a brief synopsis of the more important contraceptive methods currently available, discussed in the approximate order of their introduction to mankind. ${ }^{4}$

\section{Coitus interruptus}

Withdrawal of the male prior to ejaculation is probably the oldest contraceptive procedure known to man. It appears in the Old Testament ${ }^{5}$ and has been noted by anthropologists in various parts of the world. In western and northern Europe, where relatively late marriages have long been customary among all strata of society, coitus interruptus appears to have been the method by which the consequences of premarital love affairs were averted. Transfer of the practice into married life on

${ }^{3}$ Ronald Freedman, Pascal K. Whelpton \& Arthur A. Campbeli, Family Planning, Steriltty AND Population Growtr table 6-2, at 180 (1959).

- For a more comprehensive treatment, see Norman E. Himes, Medical History of Contraception $(1936)$.

${ }^{5}$ Genesis 38:9. 
a scale sufficient to influence the trend of the birth rate came later-in France, towards the end of the eighteenth century, and in other countries, during the nineteenth century. While some men are physically or emotionally incapable of practicing coitus interruptus, many others continue to use the method for years without apparent ill effect. It is rarely recommended by medical practitioners, however.

\section{Sponges and tampons}

Devices of this kind placed in the vagina for purposes of contraception, are mentioned in the Tosephta, a Hebrew document edited about 230 A.D., antedating the Babylonian Talmud. More recently, the sponge was recommended by Francis Place in his famous handbills-infamous, according to some-distributed in London and the industrial North of England in $1823 .{ }^{\circ}$ Doubtless these occlusive devices have been employed for a long time and are still being used to some extent throughout the world, mainly as improvised "household contraceptives" among the poor. No information is available on their effectiveness.

\section{Condom ${ }^{7}$}

A sheath or cover for the penis during intercourse made its first appearance in the eighteenth-century in England. Early condoms were made from the intestines of sheep and other animals. Since the latter part of the nineteenth centuury, these so-called skin condoms have gradually been replaced by the cheaper and more convenient rubber sheaths. In recent years, however, the manufacture of skin condoms has made a comeback in the United States, catering to the luxury market. Advocates of the skin condom cite as its principal advantage the fact that animal membrane is a better conductor of heat than a film of rubber and, therefore, interferes less with sexual enjoyment. The major inconvenience of skin condoms, the necessity of wetting the dry membrane prior to use, has been overcome by packaging them premoistened.

Prior to 1938 , a large proportion of the condoms sold in the United States were inferior in quality. In $193^{8}$, supervision over the quality of condoms was assumed by the Food and Drug Administration, which makes spot checks of shipments in interstate commerce, confiscates substandard lots, and conducts periodic factory inspections. As a result of this government supervision, the quality of condoms in the United States has greatly improved over the past two decades. It is estimated that currently about 997 out of every 1,000 rubber condoms are free from defects demonstrable by currently used tests. Domestic sales total about $600,000,000$ units per year.

The condom offers protection not only against unwanted pregnancy, but also against venereal disease. Without special instruction and elaborate preparation, it can be used in almost any situation where coitus is possible. The evidence immediately after intercourse of an intact contraceptive barrier affords a gratifying assurance to

- Himes, op. cit. stupra note 4, at 212-20.

${ }^{7}$ See generally Christopher Tietze, The Condows as a Contraceptive (1960). 
many users. Because of these advantages and because of the success of the method in their own experience, the condom is often preferred as a contraceptive by couples to whom other effective methods are also known and available.

Failure of the condom is most likely to result from a break or tear-estimated in one study to occur once in 150 to 300 instances-or from the escape of semen at the open end of the condom if withdrawal is delayed too long after orgasm. To guard against these contingencies, many clinicians recommend concurrent use of a contraceptive jelly or cream.

\section{Douches}

Plain water, vinegar, and various products widely advertised under the name of "feminine hygiene" have long been used by many women for purposes of family limitation. This was the principal method recommended in 1832 by Dr. Charles. Knowlton, ${ }^{8}$ one of the earliest American writers on the subject. Since sperm has been found in the cervical canal within minutes after ejaculation, the contraceptive effectiveness of the douche is likely to be unsatisfactory under any circumstances, and quite negligible if douching is delayed for an hour or more after intercourse.

Douching "for intimate cleanliness" is at best unnecessary for a healthy woman. It may be harmful if the product chosen is unsuitable, or the solution too concentrated, or if the woman uses the douche in an attempt at self-treatment of a pathological condition that should receive medical attention.

\section{Diaphragm}

This device was invented by a German physician, Wilhelm P. J. Mensinga, prior to $1882 .{ }^{9}$ It is the contraceptive device most often recommended by physicians in private practice and in birth-control clinics throughout the United States, where it is always prescribed in conjunction with a contraceptive jelly or cream. Thediaphragm consists of a circular spring covered with rubber, forming the rim, and a dome of soft rubber. It is inserted into the vagina, where the rim rests against the back of the pubic arch and the dome covers the cervix uteri, thus preventing the entry of sperm into the womb. Diaphragms are manufactured in various sizes, ranging from $50 \mathrm{~mm}$. to $105 \mathrm{~mm}$. in diameter, and to select the appropriate size, a pelvic examination by a physician is required, although outside the United States, mid-wives and nurses are also trained to fit diaphragms. Careful instruction in the use and care of the diaphragm is also essential.

Because the diaphragm should not remain in the vagina for more than a night, it must be inserted either daily as a bedtime routine or before each intercourse. In any event, the method makes great demands of persistent and purposeful behavior.

${ }^{8}$ Charles Knowlton, Frutrs of Philosophy, or the Private Companion of Young Married. PeOpLE (1832). See HiMes, op. cit. supra note 4, at 226-30.

${ }^{\circ}$ C. Hasse [WiLhelm P. J. Mensinga], Ueber facultative Sterilmät beleuchtet vom prophy-

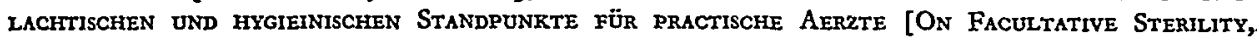
ILLUSTRATED FROM A PROPHYLACTIC AND HYGIENIC POINT OF VIEW FOR GENERAL PRACTITIONERS OF MEDICINE] (1882). 
Furthermore, the necessity of genital manipulation is repugnant to some women, and the privacy needed for successful use may be lacking in the homes of the poor.

\section{Rhythm}

The postulation of a so-called "safe period" is based on the fact, recognized independently in the early 1930's by Ogino in Japan and Knaus in Austria, ${ }^{10}$ that conception is possible during only a small fraction of each menstrual cycle. The human egg, released from the ovary two weeks prior to the onset of the next menstrual flow, remains susceptible to fertilization for an estimated twelve hours, while sperm does not survive in the female genital tract for more than about forty-eight hours.

Because very few women have absolutely unvarying menstrual cycles and most women do not remember their irregularities, the computation of the fertile and infertile or safe days of each cycle should ordinarily be made from a written record of menstruation extending over a full year. According to Knaus, the first fertile day is determined by substracting seventeen from the number of days in the shortest menstrual cycle observed during the preceding year, and the last fertile day, by subtracting thirteen days from the longest cycle.11 If, for example, the observed cycles ranged from twenty-six to twenty-nine days, the fertile period would extend from the ninth day (26-17) to the sixteenth day (29-13) of the current cycle. Others recommend a somewhat longer period of abstention; and, of course, any serious irregularity of menstruation obviously requires avoidance of sexual relations during a major portion of each cycle.

The period of abstinence may be reduced by the use of a basal body temperature chart. It has been observed that body temperatures, measured with a rectal or oral thermometer each morning before arising, are higher during the later portion of the menstrual cycle than during the earlier portion. The rise in temperature (on the order of $0.7^{\circ} \mathrm{F}$.) occurs one or two days after ovulation, when conception is no longer possible. Therefore, the temperature chart cannot be used to predict the day of ovulation.

Rhythm is the only method of fertility control, other than complete abstinence, that is sanctioned by the Roman Catholic Church, provided it is employed for serious and worthy reasons. Successful use of the method requires considerable self-control, especially from the young and sexually vigorous, reflecting strong religious motivation and an equally strong desire to control fertility. Couples who are not so strongly motivated sometimes combine the rhythm method with other methods, relying on the safe period during the early and late portions of the menstrual cycle, but using another method during the fertile days.

\footnotetext{
${ }^{10}$ Ogino, Über den Konzeptionstermin des Weibes und seine Anwendung in der Praxis [On the Time of Conception of the Female and Its Application in (Medical) Practice], 56 ZBL. F. GrN. 721 (1932); Knaus, Die periodische Frucht-und Unfruchtbarkeit des Weibes [The Periodical Fertility and Infertility of the Female], 57 ZBL. F. GYN. I393 (1933).

11 Hermann Knaus, Die fruchtbaren und unfruchtbaren Tage der Frau [The Fertile and INFERTILE DAYS OF WOMEN] (1958).
} 
Apart from miscalculation, failure of the rhythm method may result from unforeseen changes in the menstrual pattern due to illness, severe emotional upset, or other causes.

\section{Spermicides}

Jellies and creams with high spermicidal action, intended for use without a diaphragm, have been developed by the pharmaceutical industry over the past few years. Injection into the vagina is accomplished by means of an applicator, prior to intercourse. No waiting period is required, but if coitus is delayed for one hour or more, or if it is to be repeated, the insertion of additional amounts is required.

Jellies and creams as contraceptive agents have a double objective: (I) to block the external os (the opening into the cervical canal), and (2) to immobilize the sperm as quickly as possible. The contraceptive effectiveness of a jelly or cream depends, therefore, not only on the spermicidal action of the material as observed in the laboratory, but also on the physical characteristics that determine its distribution in the vagina and the necessary contact with the ejaculate.

Many physicians believe that a vaginal jelly or cream alone constitutes a less effective contraceptive than the combination of either of these materials with the diaphragm. It may be argued, however, that the injection of jelly or cream into the vagina is a much simpler procedure than the correct insertion of the diaphragm and that simplicity is conducive to more consistent contraceptive practice. To the extent that this assumption is correct, a couple may derive better protection from a simpler method, used regularly, than from a theoretically more effective procedure that is less acceptable to them.

\section{Vaginal tablets}

Although it has not been used extensively in the United States, because of low production costs and utmost simplicity in use, this contraceptive technique may become a method of the greatest importance in the "underdeveloped" regions of the world. Vaginal tablets weigh between 0.55 and 1.2 grams apiece ${ }^{12}$ and are designed to crumble and dissolve on contact with the moisture of the vagina. Most brands release carbon dioxide to produce a dense foam that is said to serve as a mechanical barrier as well as a means of distributing the spermicidal agent. After the tablet has been inserted with a finger far up into the vagina prior to intercourse, a waiting period of a few minutes is required for its disintegration.

A satisfactory contraceptive tablet must be chemically stable enough to resist deterioration in a hot and humid climate, such as India's, and at the same time be capable of dissolving rapidly and completely in the presence of a very scant amount of vaginal fluid. Clinical and field testing of vaginal tablets has yielded encouraging results. Their effectiveness seems to be comparable to that of jelly or cream alone, and the fact that no apparatus is needed for their use is a clear advantage.

${ }^{13}$ An ordinary aspirin tablet weighs about 0.3 grams. 


\section{Oral contraceptives}

In recent years, these have been the subject of considerable attention on the part of the press and the public at large. Quite obviously, the social taboos restricting the discussion of methods of family limitation apply far less rigidly to oral medication than to vaginal manipulation.

In the United States, attention has centered on the studies of Gregory Pincus ${ }^{\mathbf{1 3}}$ and others who have worked with certain substances known as I9-nor steroids. These substances are chemically related to the female sex hormone, progesterone, normally secreted by the corpus luteum in the ovary during the second half of each menstrual cycle and during pregnancy. Given daily in appropriate dosages, these drugs effectively suppress ovulation. After twenty days, the medication is suspended until menstruation occurs, and it is reinstituted five days after the onset of the flow.

Since 1956, the I9-nor steroids have been extensively tested in Puerto Rico, as well as in the continental United States. Nausea and other side-effects have been attributed to the drug by some of the users. It is possible that many of these complaints are psychosomatic in origin, unrelated to the nature of the medication. Women who discontinued the steroids conceived promptly unless they resorted to other types of birth control.

The crucial question, of course, concerns the ultimate safety of the method. No one knows with assurance the effect on the human female of continuous suppression of ovulation for a major portion of the reproductive period. Observation of laboratory animals is not always a reliable guide. It is, therefore, the considered opinion of many physicians that use of steroids for purposes of contraception should remain under close medical supervision for some time. Another serious disadvantage of the Ig-nor steroids is their high price. At present, one year's supply retails for about $\$ 130$.

Other approaches to the problem of oral contraception are now in the laboratory stage, and a few are undergoing clinical evaluation. Some of these studies point to procedures that would achieve their objective by far less radical modifications of normal physiology than suppression of ovulation through the use of steroids. The ideal oral contraceptive has not yet been invented, but one is justified in expecting important new developments in this area over the next decade.

\section{B. Extent of Use}

The most comprehensive information on the extent of contraceptive practice in the United States was obtained in 1955 from a nationwide sample of 2,7x3 white married women, eighteen through thirty-nine years of age. ${ }^{\mathbf{1 4}}$ Interviewed by highly trained investigators, these women responded freely to a long and searching questionnaire including questions on marital contraceptive practices. Only ten womenfour-tenths of one per cent-refused to answer questions relating to family limitation.

${ }^{12}$ Pincus et al., Fertility Control with Oral Medication, 75 AM. J. OBsTET. \& GrNecoL. 1333 (1958).

${ }^{14}$ FreedMan, Et al., op. cit. stipra note 3 . 
According to this investigation, known as the GAF (Growth of American Families) Study, seventy per cent of the couples had taken up the practice of birth control prior to the interview, and an additional nine per cent were planning to do so at some later date. Among the fecund-i.e., those without known impairments of reproductive capacity-ninety-two per cent of the couples married fifteen years or more had become users of contraception. These percentages exclude wives who claimed to have "douched for cleanliness only." Among couples who had never tried to prevent conception, more than three-fifths were found to be sterile or subfecund.

As is shown in table one, the extent and type of contraception varied with religious affiliation and with such socioeconomic variables as the wife's education and the husband's income. Among all couples, only fifty-seven per cent of the Roman Catholic wives reported use of contraception, compared with seventy-five per cent of the Protestant and eighty-six per cent of the Jewish wives. The corresponding proportions for fecund couples were seventy, eighty-eight, and ninety-five per cent, respectively. The extent of contraceptive practice also varied markedly by level of wife's education, ranging from forty-eight per cent for all wives who had not gone beyond grade school to eighty-four per cent for all college-educated wives. The pattern of variation by husband's income was quite similar.

The great majority of couples practicing birth control had relied on one or more of five methods: condom, diaphragm, rhythm, douche, and coitus interruptus. The condom was the last method employed prior to the interview by twenty-six per cent of all users, while the diaphragm accounted for twenty-four per cent, rhythm for twenty-one per cent, and the douche and coitus interruptus for seven per cent each.

TABLE I

Use of Contraception IN the United States, 9955 (PERCentage)

\begin{tabular}{|c|c|c|}
\hline & All Couples & Fecund Couples \\
\hline 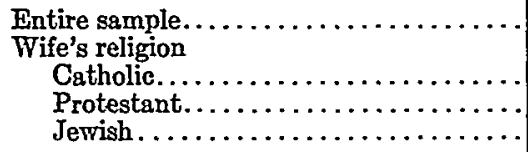 & $\begin{array}{l}70 \\
57 \\
75 \\
86\end{array}$ & $\begin{array}{l}83 \\
70 \\
88 \\
95\end{array}$ \\
\hline 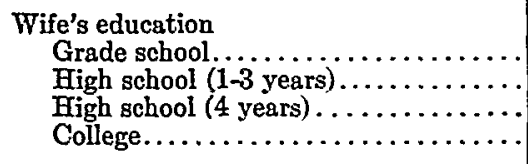 & $\begin{array}{l}48 \\
65 \\
74 \\
84\end{array}$ & $\begin{array}{l}68 \\
79 \\
85 \\
91\end{array}$ \\
\hline 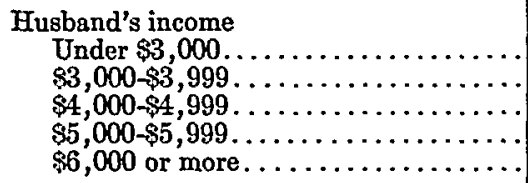 & $\begin{array}{l}58 \\
69 \\
72 \\
76 \\
79\end{array}$ & $\begin{array}{l}71 \\
83 \\
85 \\
90 \\
93\end{array}$ \\
\hline
\end{tabular}


Another five per cent represented combined or alternating use of two or more of the five methods listed. ${ }^{15}$

Among couples with Roman Catholic wives and using contraception, more than half (fifty-three per cent) reported rhythm as their most recent method and fortyseven per cent had never used any other. Conversely, fifty-three per cent had used methods disapproved by their church. Most Protestant-and to an even greater extent Jewish-couples had used appliance methods, with only eleven per cent relying exclusively on either rhythm or coitus interruptus.

Close correlations were also found between choice of contraceptive method and level of education, as well as other indicators of socioeconomic status. Use of the rhythm method was associated with advanced education among Roman Catholics and Protestants. A similar association was found for the diaphragm among Protestants and among those Roman Catholics who had experience with "artificial birth control." Conversely, use of the douche and especially of coitus interruptus were inversely associated with educational level. The condom was a popular method at all socioeconomic levels.

Nonwhite women were not included in the sample on which the above figures. are based. Data available from other studies indicate, however, that contraception is less widely practiced among the nonwhite population of the United States than among the white population.

The findings of the GAF Study have been confirmed, to a large extent, by another investigation that obtained its data on contraceptive practice from a sample of $\mathrm{I}, \mathrm{I} 65$ white couples residing in the seven largest metropolitan areas (excluding Boston) in the United States, who were interviewed in 1957 about six months after the birth of their second child. ${ }^{16}$ Most of the information refers to the period r95056. Of these couples, at least sixty-eight percent had taken up birth control prior to the first pregnancy, and eighty-four per cent, prior to the second pregnancy. Together, they reported 2,6r7 intervals-i.e., periods between marriage and first conception, between pregnancies, and between the second birth and the interviewduring which contraception had been practiced. The condom was employed as the sole method of protection in thirty-two per cent of these intervals, the diaphragm and the safe period in eighteen per cent each, and the douche and coitus interruptus in five per cent each. Combined and alternate use of several methods accounted for most of the remaining intervals. The pattern of contraceptive practice by religion and socioeconomic status is quite similar to that noted in the GAF Study.

In the United Kingdom, an investigation into the contraceptive practices of the population was conducted in 1946-47 under the auspices of the Royal College of

${ }^{15}$ The author is indebted to Professor Freedman for a special tabulation of users by last method used.

${ }^{16}$ This study has been conducted by the Office of Population Research, Princeton University, under the auspices of the Milbank Memorial Fund. The data shown here are based on a forthcoming monograph, Family Growth in Metropolitan America, by Charles F. Westoff, Robert G. Potter, Jr., Philip C. Sagi, and Elliot G. Mishler, to be published by the Princeton University Press. The authors have graciously given permission to use their material. 
Obstetricians and Gynaecologists, at the request of the Royal Commission on Population. $^{17}$ The study was based on a nationwide sample of $3,28 \mathrm{I}$ women. The sample was found to be somewhat biased in the direction of lower socioeconomic status and higher fertility, the average number of births per woman being about one-fifth above the comparable figure ascertained in the family census of 1946.

A partial comparison of the American survey of I955 (GAF Study) and the British survey of $1946-47$, limited to recently married couples-i.e., marriages of less than five years' and less than seven years' duration, respectively-is shown in table two.

\section{TABLE II}

Use of Contraception in the United States, I955, and the United Kingdom, 1945-47, among Recentux Married Couples (percentage)

\begin{tabular}{c|c|c}
\hline & American Couples & British Couples \\
\hline All couples & 65 & 55 \\
Ever using any method........ & 50 & 31 \\
Ever using appliance methods... & 1 & 24 \\
Using coitus interruptus only.... & 13 & insignificant \\
Using rhythm only........... & & \\
Users & 77 & 57 \\
Ever using appliance methods... & 2 & 43 \\
Using coitus interruptus only.... & 20 & insignificant \\
Using rhythm only............ & & \\
\hline
\end{tabular}

The major differences between the findings of the American and the British investigations were the following: ( $\mathrm{I}$ ) the use of contraception was reported by a larger percentage of all recently married couples in the United States than in the United Kingdom; (2) appliance methods had been used by substantially larger proportions of all couples and of users in the United States than in the United Kingdom; (3) reliance on the rhythm method was insignificant among the British couples, but was reported by one-fifth of recently married users in the American survey; and (4) coitus interruptus was far more widely used in the United Kingdom than in the United States.

These differences may reflect in part: (I) the bias in the British survey toward lower socioeconomic status and higher fertility, which, however, was least for the marriages of short duration; (2) in the interval of $121 / 2$ years between the dates of the two investigations, both the appliance methods and rhythm have gained in popularity in the United States; and (3) the higher proportion of Roman Catholics in the American as compared with the British population. It is believed, however, that these factors cannot fully explain the reported differences in contraceptive behavior, especially the striking divergence in reliance on coitus interruptus.

${ }^{17}$ E. Lewis-Faning, Family Limiration and Its Influence on Human Fertility During the Past Fifty Yenrs (x949). 
Within the category of appliance methods, the British survey revealed more widespread use of condoms and vaginal tablets and less use of the diaphragm than was reported by American couples.

In Japan, five successive and comparable Public Opinion Surveys on Birth Control were conducted by the Population Problems Research Council of the Mainichi Newspapers between 1950 and $1959 .^{18}$ In these surveys, information was obtained from married women under fifty years of age and their husbands. A substantial increase was noted in the proportion of couples who reported current or past use of contraception:

$\begin{array}{cc}\text { Year } & \text { Per cent } \\ 1950 & 29.1 \\ 1952 & 40.2 \\ 1955 & 52.5 \\ 1957 & 56.5 \\ 1959 & 62.7\end{array}$

In 1959, the proportion of contraceptors was higher in the six major cities of Japan (sixty-seven per cent) than in the other urban areas, and was lowest in the rural districts (fifty-nine per cent). In the same year, seventy-six per cent of the husbands with thirteen or more years of education reported use of contraception, as compared with sixty-seven per cent for men with ten to twelve years of education and only fifty-six per cent for those with nine years or less.

The condom, the most widely-used method of contraception in Japan, was reported by a majority of users in each survey since 1952. Next in popularity is the rhythm method, an example of a prophet (Ogino) honored in his own country. Combined use of the rhythm and another contraceptive method, most often the sheath, appears more common in Japan than in the United States, probably because Roman Catholics are a very small minority in Japan and the religious issue is rarely involved.

Information on the extent of contraceptive practice and on the methods used in other countries with comparatively well-controlled fertility is scanty or nonexistent. Fragmentary data now available suggest that the two methods employed by the male-i.e., coitus interruptus and the condom-account for the greater part of contraceptive practice in these areas.

\section{Effectiveness}

Study of the effectiveness of contraceptive methods requires a distinction between physiologic effectiveness on the one hand, and use-effectiveness on the other. Physiologic effectiveness, or effectiveness under ideal conditions, with no errors in technique and no omissions, is always higher than the protection achieved by the most successful groups of users. Use-effectiveness depends on such characteristics of

\footnotetext{
${ }^{18}$ See, e.g., Population Problems Research Council, Fifth Public Opinion Survey on Birth Control in JaPAN (1959).
} 
a given population as intelligence, formal education, socioeconomic background, and interest in controlling fertility.

Early students of contraception attempted to measure its effectiveness in terms of the percentages of successful and unsuccessful users. The duration of exposure to risk of pregnancy was disregarded. Today, it is known that couples who rely on a given contraceptive method for a protracted period experience more accidental pregnancies than a comparable group of couples using the identical method with the same skill and perseverance, but for a short time only. The failure to take duration of use into consideration was of particular importance when the effectiveness of the prescribed method-in this instance, the diaphragm-and-jelly-was compared with that of contraceptive practices prior to clinic attendance.

During the early history of birth-control clinics, most women who attended already had large families and many had tried to regulate their fertility over a number of years. The average period of the preclinic efforts to control family size was much longer than the time of use of the method prescribed at the clinic. Consequently, the effectiveness of the diaphragm was overestimated in relation to the popular techniques used by the same population prior to clinic attendance, especially the condom and coitus interruptus.

Today, use-effectiveness of contraception is customarily studied in terms of period of exposure to the risk of pregnancy and is measured by the failure rate, or pregnancy rate, per I00 years of use, computed by the following formula:

$$
\mathrm{R}=\frac{\text { Number of accidental pregnancies } \times \mathrm{r}, 200}{\text { Total months of use }}
$$

This method of computation was first proposed by Raymond Pearl ${ }^{19}$ in the early I930's and is often referred to as "Pearl's formula." Under this procedure, a high failure rate indicates a low level of contraceptive effectiveness, and a low rate, a high level of effectiveness.

The first study to provide comprehensive data on the effectiveness of contraceptive methods, as practiced by the general population of a large American city, was based on a sample of 1,974 white Protestant couples interviewed in Indianapolis in I $94 \mathrm{I}-42{ }^{20}$ As the period of married life covered by the histories of these couples ranged from twelve to fifteen years, the information refers to the period r927-42. All husbands and wives in the sample had completed at least eight years of formal education and had resided in large cities most of their married lives.

Omitting a minority of "relatively sterile" couples, the marital experience of the Indianapolis sample included a total of about 152,300 months of use of various contraceptive measures and $r, 567$ pregnancies during this period. The failure or pregnancy rate for all methods combined was twelve per roo years of use:

\footnotetext{
${ }^{20}$ Pearl, Contraception and Fertility in 2,00o Women, 4 Hum. BIoL. 363 (1932).

${ }^{20}$ Westoff et al., Social and Psychological Factors Affecting Fertility. XX. The Use, Effectiveness, and Acceptability of Various Methods of Fertility Control, 31 Mrlbank Memorial Fund Q. 291 (r953).
} 


$$
R=\frac{1,567 \times 1,200}{152,300}=12 \text { per 100 years }
$$

Failure rates for the most widely used methods were as follows:

$\begin{array}{llll}\text { Diaphragm } & 4 & \text { Coitus interruptus } & \text { ro } \\ \text { Condom } & 7 & \text { Douche } & \text { 2I }\end{array}$

For each method, failure rates were lowest among couples with the highest income and highest among those with the lowest income. The relatively low pregnancy rate achieved by couples using the condom is noteworthy, since most of the years of observation covered by the Indianapolis study precede the assumption of control over quality standards for condoms by the Food and Drug Administration in 1938. Available data indicate a significant improvement in the quality of condoms since that year.

More recent information on the effectiveness of contraceptive methods was obtained in 1957 in a study of metropolitan families, previously cited in this article. ${ }^{21}$ According to this survey, the following failure rates per roo years of use were obtained for the most popular methods:

$\begin{array}{llll}\text { Condom } & \text { 14 } & \text { Rhythm } & 3^{8} \\ \text { Diaphragm } & \text { I4 } & \text { Douche } & 4 \mathrm{I} \\ \text { Coitus interruptus } & \text { I7 } & & \end{array}$

Although these failure rates are substantially higher than those reported in the Indianapolis study, there is no apparent reason to believe that these differences would affect the ranking by effectiveness of the contraceptive methods used. At least two factors contributed to the higher failure rates: $(\mathrm{r})$ owing to the design of the sample, contraceptive practice was always followed by a pregnancy, planned or unplanned; and (2) few of the couples tried to postpone their pregnacies by more than two or three years. Therefore, the most efficient contraceptors among them did not contribute as large a proportion of the total period of use as was the case in the Indianapolis study.

According to the investigation into the contraceptive habits of the British population, mentioned earlier, ${ }^{22}$ the failure rate among married British couples for the approximate period $1935-47$ was only six per roo years of use of appliance methods of contraception. The failure rates published were limited to experience with all appliance methods combined-condom, diaphragm-and-jelly, and others. No rates were published for the individual methods. Couples relying on nonappliance methods (almost entirely coitus interruptus) experienced a failure rate of eight per Ioo years of use, only slightly more than those relying on the more modern devices.

${ }^{21}$ See note 16 supra.
${ }^{22}$ See note I7 supra. 
III

\section{SterILIZATION}

Permanent sterilization is ordinarily accomplished in women by salpingectomyi.e., by the cutting, ligation (tying), and partial removal of the Fallopian tubes or oviducts, through which the egg moves from the ovary to the uterus and in which it meets the sperm and undergoes fertilization. Ligation alone is not sufficient to achieve reliable closure of the tube. In the male, the sterilizing operation (vasectomy) consists of the cutting, ligation, and removal of a small portion of the spermatic duct or vas deferens. Since sterilization does not involve removal of the sex glands in either sex-i.e., the ovaries of the female or the testicles of the male-internal secretion is not affected. The operation has, therefore, none of the consequences associated with castration in men and animals. It does not produce loss or impairment of sexual desire or of capacity for sexual response, nor does it lead to changes in the body other than those intended.

While salpingectomy is a major operation, requiring the opening of the abdominal cavity and hospitalization, the period of bed rest is hardly lengthened if tubal sterilization is performed immediately following delivery, by Caesarean section or otherwise.

It is difficult to estimate the risk of life involved in tubal sterilization, since it is so frequently performed with other surgical procedures. It would appear, however, that about one death per 3,000 cases can be directly attributed to the sterilizing operation. In the male, on the other hand, vasectomy can be performed through a small incision in the scrotum or in the groin, under local anesthesia, and does not require hospitalization. Risk to life is practically nil.

Neither tubal sterilization nor vasectomy is roo per cent successful. With a reasonable degree of surgical skill, however, the number of failures is relatively small, and the effectiveness in controlling fertility is far superior to any contraceptive method now available. According to ten major studies published in the United States since 1948 and covering about ro,000 women on whom salpingectomy had been performed, ${ }^{23}$ the incidence of known pregnancies during a follow-up period of several years was on the order of one per cent. For the most frequently-used operative technique, the failures amounted to only 0.4 per cent. Information on the success of vasectomy is difficult to obtain. Fragmentary information suggests that failures are more common than in the female sex.

Attempts to restore fertility by a second operation have been made in a limited number of cases involving both tubal sterilization and vasectomy. The results of these efforts have not been encouraging. In general, therefore, surgical methods

${ }^{23}$ Reports by Dieckman-Hauser, Gilbert, Irving, Lull-Mitchell, Lee-Randall-Keettel, Weinbaum-Javert, and Prystowsky-Eastman; cited by Garb, A Review of Tubal Sterilization Failures, r2 Orstet. \& GrNecol. Survey 291 (1957); Dieckman \& Harrod, Tubal Ligation by a Modified Madlener Method, 68 AM. J. OBSTET. \& Gynecol. 897 (I954); August, Sterilization of Women, 5 OBsTet. \& GrNecoL. 715 (1955); Guttmacher, Puerperal Sterilization on the Private and Ward Services of a Large Metropolitan Hospital, 8 FERTIL. \& STERIL. 59 I (I957). 
of fertility control are irreversible. This fact restricts their application to persons permanently ineligible for parenthood because of serious illness or for eugenic reasons, such as mental deficiency, and to mature couples who have all the children they want or are likely to want in the future.

There is no agreement among physicians as to the number of children after which voluntary sterilization should be considered. In Zurich, three living children constitute an adequate reason for sterilization, while in the United States, a much larger number is usually required in the absence of specific medical indications. Many hospitals in this country do not permit voluntary sterilization for multiparity alone, and hospitals under Roman Catholic control do not permit sterilization under any circumstances.

According to a number of studies, ${ }^{24}$ the great majority of sterilized patients are satisfied with the result, feel relieved from the nagging fear of pregnancy, and have no complaints. Regrets and more serious psychological side-effects have, however, been occasionally noted in sterilized persons of both sexes, apparently more often in women than in men, who were poorly and/or not suitably prepared for the opera. tion. Such undesirable side-effects are most likely to occur in situations where the marriage has been unhappy, perhaps on the brink of breaking up, and when the operation was accepted reluctantly under pressure from a spouse or from other persons.

While comprehensive statistics on the incidence of surgical sterilizations in the United States are lacking, some relevant information can be derived from the GAF Study previously cited. ${ }^{25}$ An operation that made pregnancy impossible was reported by nine per cent of the interviewed wives, including a few who reported an operation on the husband. As is shown in table three, the percentage was much higher for the older wives than for the younger ones and much lower among Roman Catholics than in the sample as a whole.

TABLE III

Incidence of Surgical Sterilization of Women in the United States (phrcentage)

\begin{tabular}{c|c|c|c}
\hline .. Age & Entire Sample & Roman Catholics & Difference \\
\hline 18-29 years..... & 4 & 3 & 1 \\
$30-39$ years..... & 13 & 6 & 7 \\
\hline
\end{tabular}

\footnotetext{
^s Binder, Psychiatrische Untersuchungen über die Folgen der operativen Sterilisierung der Frau durch partielle Tubenresektion [Psychiatric Investigations of the Consequences of Sturgical Sterilization of Women by Partial Resection of the Tubes], 40 Schwelz. Arch. Neurol. Psychiatr. I, 249 (1937); Naville, Nachuntersuchungen bei 195 auf eigenes Begehren ohne vorherige psychiatrische Begutachtung sterilisierten Frauen [Follow-up Investigations of 195 Women Sterilized at Their Own Request Without Previous Psychiatric Examination], 41 Praxis rozo (1952); Hauser, Die Sterilisiertung des Mannes zurr Verhütung von Schwangerschaften [The Sterilization of Men to Prevent Pregnancy], 44 Praxis 477, 500 (1955).

${ }_{25}$ FREEDMAN, ET AL., op. cit. supra note 3 .
} 
According to information volunteered by some of the respondents, the operation was performed to prevent further childbearing. In other cases, the sterilizing effect was incidental to the correction of a pathologic condition, such as the removal of a tumor. In many instances, however, the reason for the operation was not ascertained.

In this situation, the incidence of operations performed for the purpose of fertility control must be estimated by an indirect approach, based on the fact that such operations are prohibited by the Roman Catholic Church and on the assumption that Roman Catholic couples respect this prohibition. As there is no reason to believe that pelvic pathology requiring surgical correction is less common among Roman Catholics than among women of other denominations, the difference between Roman Catholics and the entire sample-one per cent for the younger wives and seven per cent for those in their thirties-may serve as a rough estimate of the incidence of sterilization for the purpose of fertility control. This estimate would be a minimum figure, however, since the assumption is certainly not correct that no sterilizations as such are performed on Roman Catholic women.

Extrapolating the results of our computation to the total population of the United States, we may conclude that there were in 1955 at least $1,200,000$ persons of reproductive age, mainly women, who had chosen permanent surgical protection against unwanted pregnancy. The corresponding minimum estimate of the annual number of sterilizations during the decade preceding 1955 is on the order of $75,000,{ }^{26}$ including operations other than salpingectomy and vasectomy, but performed for the purpose of family limitation. It is believed that the number of sterilizing operations has declined in recent years, since many hospitals have adopted restrictive policies.

Information on voluntary sterilization is not available for any one of the major European countries. In Japan, 291,000 operations on women and 9,000 on men, performed under the Eugenics Protection Law during the decade 1949-58, were reported to the authorities; for the period $1955-58$, the annual figures remained fairly constant at about 42,000 and 1,700 , respectively. ${ }^{27}$ The reported totals doubtless fall short of the actual figures. According to a survey of family-limitation practices conducted in 1959 by the Population Problems Research Council, ${ }^{28}$ there are in Japan about 500,000 to 600,000 wives under fifty years of age who, or whose husbands, had undergone sterilization. The number of sterilized wives exceeds the number of husbands by a ratio of about six to one. Since the population of Japan is about half that of the United States, the incidence of sterilization in the two countries is approximately the same.

\footnotetext{
${ }^{20}$ It is interesting to compare these figures with only 61,000 sterilizations performed under the eugenic laws of 27 states from 1907 through 9958 . See HuMan Betrerasent Ass'N of AMERica, Sterilizations Reported in the UntTed States to January I, x959 (I960).

${ }^{27}$ Reports of the Ministry of Welfare, made available through the courtesy of Dr. Minoru Muramatsu, Tokyo.

${ }^{28}$ Sec note 18 supra.
} 


\section{IV}

Abortion

Termination of unwanted pregnancies by destruction of the fetus-i.e., by induced abortion-has been practiced throughout man's history. Some cultures prescribe abortion under specific circumstances; others tolerate it; still others condemn it. In the United States, the laws of most states stipulate prevention of the death of the pregnant woman as the sole legal ground on which pregnancy may be interrupted. This permission is extended-in a few states by statutes, and elsewhere in fact-to cases where a serious threat to health is to be averted. In practice, certain eugenic indications (e.g., German measles, erythroblastosis) are also recognized. The interpretation of the law by physicians and hospital administrators is, as a rule, on the conservative side. In New York City, the only jurisdiction where all fetal deaths must be registered by law, the number of therapeutic abortions equals about one-fifth of one per cent of the number of live births.

In certain other countries, such as Denmark and Sweden, the interpretation of medical necessity for abortion is far more liberal, taking into account less serious threats to the woman's health as well as her economic situation. In addition, the laws of these countries permit abortion for eugenic and so-called humanitarian reasons. The latter category, infrequently used, refers to pregnancies resulting from certain offenses against the penal code, such as rape and incest. The incidence of legal abortions reached its maximum in Sweden in 1951 with 5.7 per cent, and in Denmark in 1955 with 7.I per cent of the number of live births. By 1958, legal abortions had dropped in Sweden to 2.4 per cent, and in Denmark to 5.2 per cent of the number of live births. ${ }^{2 \theta}$

The liberal Scandinavian laws on abortion have permitted the compilation of reliable statistics on mortality and morbidity associated with induced abortion performed on relatively healthy women. The most recent available figures, for the period 195357, are shown in table four. The most common complications were fever

TABLE IV

Legal Abortions in Scandinavia, 1953-57

\begin{tabular}{|c|c|c|c|c|}
\hline \multirow[b]{2}{*}{. } & \multirow[b]{2}{*}{ Country } & \multirow[b]{2}{*}{ Legal Abortions } & \multicolumn{2}{|c|}{ Rate per 100 Abortions } \\
\hline & & & Deaths & Complications \\
\hline . & Denmark ${ }^{30}$ & 23,666 & 0.07 & 2.9 \\
\hline & Sweden $^{31}$. & 21,803 & 0.06 & 5.6 \\
\hline
\end{tabular}

So Tieze, Legal Abortion in Scandinavia, 16 Q. Rev. Surgery, Obstet. \& Grnecol. 227 (1959). The data for 1958 have been made available through the courtesy of Dr. Malcolm Tottic, Stockholm, and Mrs. Marie Lindhardt, Copenhagen.

${ }^{80}$ Berthelsen \& $\emptyset$ stergaard, Lethality and Incidence of Complications in Therapeutic Abortion in Denmark, 1953-1957, 6 DANISH MED. BuLl. Iro (1959).

${ }^{31}$ Medicinalstyrelsen, Allä̈n hälso- och syekvỉe 1957 [Public Health and Care of the Sick I957], at 64 (r959). 
and hemorrhage. It need not be emphasized that abortions performed illegally, often by persons with no medical background and under unsanitary conditions, are more likely to result in death or illness than operations done by well-trained physicians in hospitals.

Legalized abortion is currently available unconditionally or with a minimum of formal requirements, in Japan, in the Soviet Union, and in most of the People's Democracies of eastern Europe. Table five shows the trend of legal abortions in Japan, performed under the Eugenics Protection Law, and reported to the authorities. $^{32}$ The actual total is believed to exceed the number reported by several hundred thousand, owing-it has been alleged-to the reluctance of physicians to pay income tax on their full earnings. Rapidly increasing numbers and rates of legalized abortions do not necessarily imply equally rapid increases in total abortions, since, to some extent, illegal abortions are replaced by legal interruptions of pregnancy.

TABLE $V$

Live Births and Induced Abortions in Japan, I949-58

\begin{tabular}{|c|c|c|c|c|}
\hline \multirow{2}{*}{ Year } & \multicolumn{2}{|c|}{ Number (thousands) } & \multicolumn{2}{|c|}{ Rate (per 1000 population) } \\
\hline & Births & Abortions & Births & Abortions \\
\hline $\begin{array}{l}1949 \ldots \ldots \ldots \ldots \\
1950 \ldots \ldots \ldots \\
1951 \ldots \ldots \ldots \\
1952 \ldots \ldots \ldots \\
1953 \ldots \ldots \ldots \\
1954 \ldots \ldots \ldots \\
1955 \ldots \ldots \ldots \ldots \\
1956 \ldots \ldots \ldots \ldots \\
1957 \ldots \ldots \ldots \ldots \\
1958 \ldots \ldots \ldots \ldots\end{array}$ & $\begin{array}{l}2,696.6 \\
2,337.5 \\
2,137.7 \\
2,005.2 \\
1,868.0 \\
1,769.6 \\
1,730.7 \\
1,665.3 \\
1,566.7 \\
1,649.8^{*}\end{array}$ & $\begin{array}{r}246.1 \\
489.1 \\
638.4 \\
798.2 \\
1,068.1 \\
1,143.1 \\
1,170.1 \\
1,159.3 \\
1,122.3 \\
1,128.2\end{array}$ & $\begin{array}{l}32.8 \\
28.2 \\
25.1 \\
23.5 \\
21.5 \\
20.1 \\
19.4 \\
18.5 \\
17.2 \\
18.0\end{array}$ & $\begin{array}{r}3.0 \\
5.9 \\
7.6 \\
9.3 \\
12.3 \\
13.0 \\
13.1 \\
12.9 \\
12.3 \\
12.3\end{array}$ \\
\hline
\end{tabular}

* Preliminary.

The incidence of illegal abortion may be as high in some countries as the incidence of legal abortion in Japan, or even higher. Accurate statistics or even reliable estimates are, of course, lacking. For the United States, a committee appointed by the Conference on Abortion at Arden House, New York, in April r955, concluded its report with the observation that: ${ }^{33}$

A plausible estimate of the frequency of induced abortion . . . could be as low as 200,000 and as high as $1,200,000$ per year .... There is no objective basis for the selection of a particular figure between these two estimates as an approximation of the actual frequency. The lower limit corresponds to slightly more than one per $\mathrm{r}, 000$ population, and the upper limit, to about seven per I,00o.

Compared with the interwar period, the incidence of illegal abortions has probably declined in the United States-possibly also the total number-in spite of a larger population. There are four reasons for this assumption: (I) a trend to earlier

${ }^{32}$ See note 27 supra; U.N. DeP't of Economic and Social AfFairs, Demographic Yearbook 212-I3 (U.N. Pub. Sales No. I959.XIII.I).

${ }^{33}$ Mary S. Calderone (Ed.), Abortion in the United States i80 (1958). 
marriages and somewhat larger families; (2) more widespread use of contraception, especially of the more effective methods; (3) improved quality of condoms and other materials; and (4) more vigorous enforcement of existing laws, which has driven a number of abortionists out of business. The assumed downward trend of illegal abortion may also be reflected in declining numbers of deaths attributed to abortion, as is shown in table six. The principal reason for the decline of mortality from abortion, however, is the steady improvement in methods of treatment, especially the introduction first of sulfa drugs and later of penicillin and other antibiotics.

TABLE VI

Deaths Attributable to Abortion in the United States, $1933-57^{34}$

\begin{tabular}{|c|c|c|}
\hline Period & $\begin{array}{l}\text { Number of Deaths } \\
\text { (annual average) }\end{array}$ & $\begin{array}{l}\text { Rate of Deaths (per } \\
\text { million women, 15-44 } \\
\text { years of age) }\end{array}$ \\
\hline $\begin{array}{l}1933-38 \ldots \ldots \ldots \ldots \ldots \\
1939-43 \ldots \ldots \ldots \ldots \ldots \ldots \\
1944-48 \ldots \ldots \ldots \ldots \ldots \ldots \\
1949-53 \ldots \ldots \ldots \ldots \ldots \ldots \\
1954-57 \ldots \ldots \ldots \ldots \ldots\end{array}$ & $\begin{array}{r}2,090 \\
1,490 \\
745 \\
325 \\
258\end{array}$ & $\begin{array}{r}79 \\
45 \\
22 \\
9 \\
6\end{array}$ \\
\hline
\end{tabular}

\section{ConcLusion}

In summary, then, fertility control has been achieved in the demographically advanced countries by the use of contraception, sterilization, and abortion, legal or illegal. From the medical point of view, several methods of contraception offer high levels of protection, with no risk to health. Sterilization and abortion have attained a high level of safety, but there remains a small risk to life. Acceptance by the public, including members of the medical profession, varies among individuals; moral and legal sanctions, among communities.

${ }^{34}$ Data for 1933-45: Tietze, Abortion as a Cause of Death, 38 AN. J. Pur. Healtri I434 (I948); for 1946-56: U.S. Public Health Service, National Office of Vital Statistics, Dep't of Healtit, Education and Welfare, Vital Statistics of the United States; for 1957: 50 Vital StatisticsSPECIAL Reports 324 (I959). 